\section{The price isn't right}

ITER will cost more to build than previously thought. Now is the time to be honest about how much.

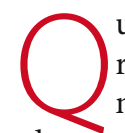
uoting a price for a major new scientific instrument is notoriously tricky. Researchers have to estimate costs for equipment that has never been built, forecast expenditures years in advance, allow for unknown contingencies, and win approval from sceptical politicians who always want the project to cost less.

So it is not a complete surprise that a recently finished design review of ITER, a major fusion experiment to be built in Cadarache, France, is forecasting a delay of $1-3$ years in its completion date and a roughly $25-30 \%$ increase in its $€ 5$-billion (US\$7.8-billion) construction cost (see page 829 ).

The seven international partners in ITER (the United States, the European Union, Russia, China, Japan, India and South Korea) will no doubt be displeased by the news. They reached a final agreement to go ahead with ITER in 2006 based on a partially incomplete 2001 design, and may well suspect that the scientists were deliberately quoting an over-optimistic price in order to sell the project.

Whatever truth there might be in that allegation, the fusion community was making its estimate under less than ideal circumstances. ITER had been something of a political football since 1985, when it began life as part of the cold war détente. The collapse of the Soviet Union began a decade of political limbo for the project. Scientists had to radically downsize it at the end of the 1990s to appease the budget concerns of skittish member states.

As international partners came and went (and, in the case of the United States, came again), ITER subsisted on a shoestring. Meanwhile, politicians fought over the project's location. Until that debate was settled in mid-2005, only limited revisions to the design could be done. The redesign has been a top priority for the new ITER team ever since, and the group should be commended for coming forward with a higher estimate of costs after the full review.

What is worrying is that even this new price tag might not reflect the true cost of the machine. Crucially, it does not include the soaring price of commodities such as steel and copper, which are used in large quantities in the giant reactor. The ITER team claims that these costs can be excluded because individual member states will contribute finished components rather than raw materials, but this seems disingenuous. Already, the US government has doubled its estimated maximum contribution to the project, and other countries will probably have to follow suit.

This suggests that ITER may yet fol-

"ITER may yet follow
the path of other
projects whose
costs spiralled out
of control"
low the path of other projects whose costs spiralled out of control once they were given a political imprimatur. The danger to the project itself may seem to be limited because of its international nature, but strictly speaking there is nothing to prevent a cancellation of the sort that ended the US Superconducting Supercollider. Congress halted that experiment 15 years ago, even as the tunnels were being dug in Waxahachie, Texas.

The more likely outcome is that overruns will further undermine the credibility of science at a time when it is increasingly dependent on multinational collaborations to build instruments and data networks. Future projects such as the International Linear Collider, a next-generation particle accelerator for high-energy physics, may well face more sceptical funders if ITER's costs aren't contained.

The independent scientific and management advisory committees overseeing ITER should take a hard look at whether the latest estimates are truly realistic. If they are not, then the committees should demand that the budget include adequate contingencies for factors such as increased energy and commodity costs, as well as scenarios for construction with less than full funding. Even if it means more pain in the short run, this kind of discipline will ultimately lead to a better machine and a better future for all international collaborations.

\section{Open to interpretation}

\section{The use of 'dignity' as the foundation for an ethical law in Switzerland is compromising research.}

T he law introduced by Switzerland in 2004 to protect the dignity of animals, plants and other life forms is now in conflict with the country's research agenda. Two top Swiss universities have been forced to appeal to the supreme court in a bid to secure the right to perform perfectly reasonable experiments that have been banned because they are said to offend the dignity of the non-human primates involved. The problem in this instance lies in an interpretation of the law that flies in the face of research reality (see page 833).

The Swiss law is at odds not only with beneficial research but also with good sense. Even plant scientists potentially face restrictions on the kinds of genetic engineering they are allowed to do (see Nature 452, 919; 2008), and debates have arisen about the abuse of dignity in decapitating wild flowers.
Although pondering the dignity of dandelions is downright silly, the underlying problem with the Swiss law is that it allows rules to be built on the foundation of a notoriously subjective concept. In March, the US President's Council on Bioethics produced a collection of 28 essays on the dignity of human life and proved unable to come to a consensus. The essays offer statements on the concept that are often contradictory: dignity is earned, but it is also shared by all in full measure. Dignity cannot be taken away - yet it can and has been in cases of slavery. Harvard psychologist Steven Pinker wrote a powerful critique of the panel's efforts in the 28 May issue of The New Republic, arguing that 'dignity' has been widely misused to mean whatever conservative bioethicists want it to mean.

Dignity as a concept cannot be a director of moral judgement. After all, when the Swiss government assigned dignity to plants, it was in essence assigning autonomy, as if a plant sways in the breeze because it has decided to do so. A strict interpretation of such a framework would prohibit agriculture. But even where such rules are not absurd, laws should not be based on such a slippery concept. 